\title{
Qualitative Parental Perceptions of a Paediatric Multidisciplinary Team Clinic for Prader-Willi Syndrome
}

\author{
(D) Jennifer S. Cox ${ }^{1}$, (D) Claire Semple2, (D) Rhian Augustus ${ }^{2}$, (D) Melanie Wenn², (D) Shelley Easter², (D) Rebecca Broadbent ${ }^{2}$, \\ (D) *Dinesh Giri2,3, (D) *Elanor C. Hinton 1 \\ ${ }^{1}$ National Institute for Health Research, Bristol Biomedical Research Centre, University Hospitals Bristol NHS Foundation Trust and University of \\ Bristol, Bristol, United Kingdom \\ 2Department of Paediatric Endocrinology, Bristol Royal Hospital for Children, Bristol, United Kingdom \\ ${ }^{3}$ Bristol University, Department of Translational Health Sciences, Bristol, United Kingdom \\ *authors contributed equally
}

\begin{abstract}
What is already known on this topic?
Prader-Willi syndrome is a complex, multisystemic, neurodevelopmental genetic disorder. Clinical symptoms vary with age and include infantile hypotonia, hyperphagia, excessive weight gain, endocrine dysfunction, behavioural problems and psychiatric issues. Guidelines recommend a multidisciplinary team (MDT) approach to provide a multi-faceted approach to manage the diverse symptoms.
\end{abstract}

\section{What this study adds?}

Medical and social care access varies greatly, and no family had previously accessed an MDT. Parents valued the connection with the specialist clinical team and with other families. Parents perceived an MDT clinic to be an efficient way to manage appointments and receive integrated timely support.

\section{Abstract}

Objective: This preliminary review was conducted to inform the design of a new service to support families with children with PraderWilli syndrome (PWS). Families were invited to attend a pilot clinic at a hospital outpatient department, comprising appointments with a multi-disciplinary team (MDT).

Methods: Following the clinic, families $(n=6)$ were invited to take part in semi-structured qualitative interviews that were audio-recorded, transcribed and analysed using thematic analysis.

Results: Families reported that the clinic offered enhanced support in the following categories: integrated care; professional input; signposting to social support (respite and financial); connection with the wider PWS community; and behavioural support.

Conclusion: This is the first paper that documents the parental perspective of an MDT clinic for children with PWS. The families felt an MDT clinic was superior to current care, offering more convenient access to an enhanced service, which would provide integrated and consistent care for their children's diverse, challenging and changing needs.

Keywords: Paediatric, Prader-Willi syndrome, multi-disciplinary team, qualitative

\section{Introduction}

Prader-Willi syndrome (PWS) is a neurodevelopmental genetic disorder caused by a lack of expression of the q11-q13 region on paternal chromosome 15 and has three genetic subtypes (1). The incidence of PWS is approximately 1 in 15,000 people (1). Clinical symptoms vary with age and the earlier symptoms include infantile hypotonia, failure to thrive, short stature, hypogonadism and other endocrine dysfunctions. Symptoms developing later include hyperphagia and excessive weight gain, if left uncontrolled. PWS is also associated with behavioural
Address for Correspondence: Jennifer S. Cox MD, National Institute for Health Research, Bristol Biomedical Research Centre, University Hospitals Bristol NHS Foundation Trust and University of Bristol, Bristol, United Kingdom

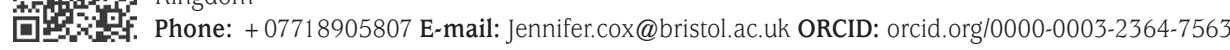

${ }^{\circ}$ Copyright 2021 by Turkish Pediatric Endocrinology and Diabetes Society

The Journal of Clinical Research in Pediatric Endocrinology published by Galenos Publishing House.
Conflict of interest: None declared

Received: 10.03 .2021
Accepted: 14.08 .2021

Received: 10.03 .2021
Accepted: 14.08 .2021 
problems such as tantrums, self-harm and psychiatric issues $(1,2,3,4,5)$.

The multifaceted nature of this disorder provides challenges to clinicians, and medical care alone may leave needs unmet (6). A multidisciplinary team (MDT) clinic has been recommended as it provides a patient-centred, biopsychosocial approach to treatment $(3,6)$. In an MDT clinic patients are seen by a wider range of health professionals equipped to support with behaviour, diet and community connections, and attending an MDT clinic has been shown to improve mortality and morbidity (6).

MDT clinics for PWS are not widespread across the UK. There is no specialist MDT clinic that can be accessed by the patients in the South West of EnglandAs part of a funding bid to initiate a clinic in this region of England, a single pilot MDT PWS clinic was conducted. Due to the low prevalence of PWS (5), the clinic would support families across a wide geographical area. To ensure the future clinic was designed around patients' needs, the parents who attended this pilot clinic were asked to take part in a qualitative review that discussed the needs of their family and their perceptions of the clinic. Whilst several recent articles have reported that an MDT is the best model of care for children with PWS and their families from a health professional point of view $(3,6,7)$, this preliminary work, for the first time, presents the parents' perspective of an MDT PWS clinic.

\section{Methods}

\section{Experimental Subjects}

Families $(n=6)$ were selected from the regional database of children with PWS and confirmed their willingness to attend a pilot clinic. Participant characteristics are detailed in Table 1. On invitation, parents were informed about the opportunity to provide feedback. On arrival, a member of the clinical team introduced the clinic and the research team. All six sets of parents agreed to participate in the review and were consented by the research team. The families at current care varied but typically included a large number of appointments with a range of health professionals, with some accessing support through their child's special education school and some through endocrine or weight management clinics, and others via PWS charities. One family had disengaged with their current NHS PWS care.

Interviews were conducted by $\mathrm{EH}$ (researcher) and JC (researcher) who were external to the clinical team and accompanied by RA (social worker). Interviews took place on a single day, in an outpatient ward of a large community hospital, where the clinic would likely be held if funded.
Interviews were carried out in a private appointment room, adjacent to the clinical team. Interviews were semistructured (See Appendix 1 for interview schedule). Three interviews took place prior to the clinic appointments; five took place after, with clinic scheduling allowing two families to be interviewed both before and after the clinic appointments, resulting in eight interviews in total. All interviews were audio recorded using a dictaphone. The duration of each interview was between 10 and 25 minutes.

\section{Data Analysis}

Interviews were transcribed verbatim by external, approved services and were anonymised. Thematic analysis was used to code the transcripts independently by two researchers due to its applicability in this type of study (8). The same two then met to refine coding as part of the iterative analysis process. Transcripts were re-read and recoded with amendments. Sub-themes and overarching themes were decided upon collaboratively.

The service review had approval from the Patient Experience and Involvement Team at University Hospitals Bristol and all interviewees provided informed consent.

\section{Interventions}

The clinic itself comprised three appointments. First, families were seen by the consultant paediatric endocrinologist, a weight management nurse specialist, and a paediatric endocrine nurse specialist. The clinic also included a consultant adult psychiatrist with an interest in PWS as a voluntary observer. Secondly, patients were seen by a clinical psychologist and a dietician together. Finally, patients were seen by the social worker, who also participated in the clinic interviews.

\section{Main Outcome Measures}

The interviews sought to explore parents' experience of the MDT clinic compared with their previous care and understand the areas of greatest need for families. They sought to engage parents in the design of both the structure and the content of the clinic, and thus feedback was requested to facilitate co-design.

\section{Results}

Each of the identified themes, shown in Figure 1, will be presented in turn along with illustrative quotes in Table 2.

\section{Integrated Support}

Overall, parents perceived the clinic to both enhance their access to support and be an improved delivery mode 


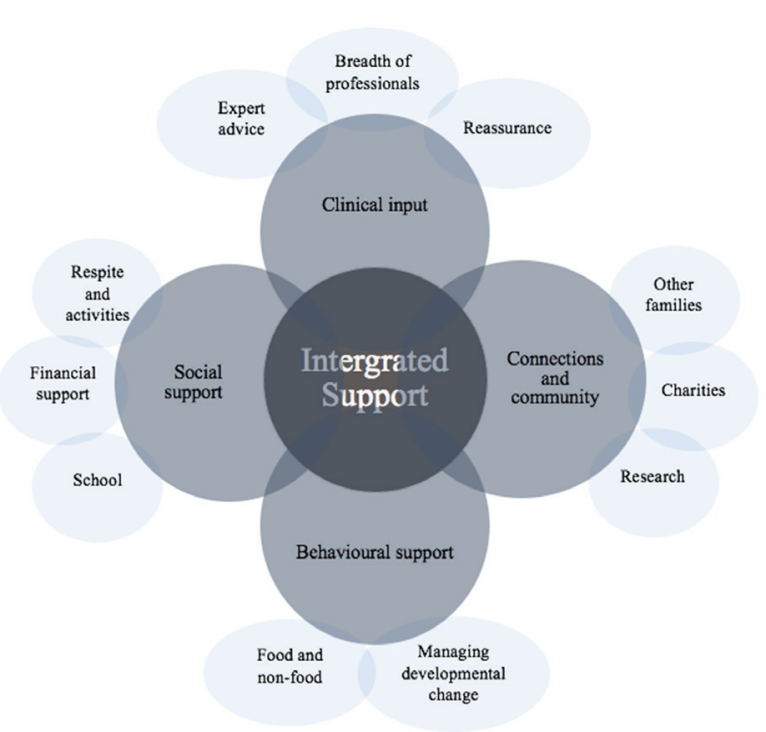

Figure 1. Families experienced integrated support from an MDT led clinic

\section{MDT: multidisciplinary team}

when compared to current care. Whilst families valued appointments with the endocrinologist - the typical care received by most families - they felt the MDT approach to be superior. Importantly, parents felt that an MDT clinic would enable a more "joined-up" approach to their care, facilitating collaborative, coordinated strategies without lengthy referral times (Table 2, 1a).

The clinic offered families a "one-stop-shop" reducing the disruption and time-off school caused by multiple appointments. This was beneficial when considering their children's need for routine and gave parents the freedom to better manage other life commitments (Table 2, 1b). Whilst families acknowledged the sometimes-lengthy travel time to reach the clinic, parents felt it was acceptable to facilitate access to this breadth of support (Table 2, 1e).

\section{Clinical Input}

\section{Access to Health Professionals}

Families typically had, or had previously had, frequent contact with a wide range of medical professionals but there was a large disparity in access to services. Some special schools were reported to host clinics but this access was not available to all families. Most noted they only had regular contact with an endocrinologist, therefore access to other health professionals at a single clinic was praised (Table 2, 2a).

Families felt that it was beneficial to see every staff member present at the clinic. In addition, families recommended that the inclusion of speech and language teams (Table $2,2 \mathrm{~b}$ ), physiotherapists, orthotics, and creative therapies

\begin{tabular}{lll}
\hline Table 1. Participant characteristics & & \\
\hline & $\begin{array}{l}\text { Patients } \\
(\mathrm{n}=6)\end{array}$ & $\begin{array}{l}\text { Parents } \\
(\mathrm{n}=9)\end{array}$ \\
\hline $\begin{array}{l}\text { Characteristics } \\
\text { Female }\end{array}$ & $\mathrm{N}$ & $\mathrm{N}$ \\
Ethnicity & 5 & 6 \\
$\begin{array}{l}\text { Caucasian } \\
\text { Age }\end{array}$ & & \\
$<5$ & 6 & 9 \\
$5-11$ & & \\
$12+$ & 3 & \\
\hline
\end{tabular}

would enhance the service further. Parents discussed how the inclusion of a play-worker would improve the impact of the clinic by providing a distraction for younger patients and supervising older children, thus reducing the need for parental supervision. One example of a benefits of this would be that parents of older children would be able to converse more candidly with clinicians about difficulties without these discussions taking place in front of the child (Table 2, 2c).

\section{Expert Advice}

Some parents were highly informed about best-practice in other clinics in the UK and internationally and were keen to ensure their child had the same access to current, top quality care (Table 2, 2d). They had participated in these interviews in part, to ensure staff connected with, and replicated the programmes running elsewhere and recommended that staff work collaboratively with charities to access specialist training (Table 2, 2e).

\section{Reassurance}

Other families explained that the greatest benefit to attending a specialised PWS clinic was to be able to "check in" with professionals, to ensure they were doing everything they could for their child. This reassurance renewed their sense of strength as parents, restoring their energy to maintain the levels of care required (Table 2, 2f).

\section{Behavioural Support}

Parents felt strongly about pro-actively managing children's behavioural problems and felt that the pilot clinic had already given them helpful strategies to implement.

\section{Food and Non-food Management}

Parents explained that as behavioural problems were often triggered by food, seeing the dietitian and psychologist together enabled them to fully explore the relevant issues (Table 2, 3a). Strategies for wider behaviour management 


\section{Table 2. Illustrative quotations}

(1a) To have those professionals together, that is a success in itself, because they communicate then. The fact that the dietician is in the same place, if there's an issue with the weight, we can go straight in and see the dietician." (Mother to Belinda, after)

Integrated
support
(1) come to one place and to see all these different people, that's been really good" (Mum to Freya, after)
(1d) "I was saying, "I hope it's worth the trip this time," because we didn't really know what to expect. Yes, if it was something like this, it would
be definitely worth the trip" (Mother of Freya, after)

Professional input (1d) "I was saying, "I hope it's worth the trip this time," because we didn't really know what to expect. Yes, if it was something like this, it would definitely worth the trip" (Mother of Freya, after)

\section{(2a) “Yes, so we go to endocrinology. We don't see a dietician anymore; we don't see physio. She has speech through school” (Mother of Belinda, after) \\ Breadth of professionals (2c) "To have play leaders here or play workers, because obviously there is stuff that you want to talk about, you can't talk with your child present, (2b) "Language and communication would be good. We did see speech and language at school, but we haven't seen her for about a year" (Mother of Abigail, before) but to have a play team available in these clinics $[\ldots]$ a lot of things are really big triggers for her at the moment, and I imagine for others with Prader-Willi of a similar age, they'd struggle. Sometimes anyway even when she was younger, you don't necessarily want to say the really bad stuff in front of your own child" (Mother of Alice, after) \\ (2d) ““'Why don't we have that? I'd love access to something like that." So, I think this is ideal” (Mother of Belinda, before)

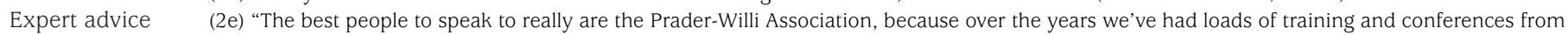 them" (Mother of Alice, after) \\ (2f) "Feeling that you can go back, having some questions answered that, maybe, have been making us feel like we're not doing the best job Reassurance sometimes, to then being able to get some support with that and then go home and start to feel better again and like we're ready to tackle that" (Mother of Freya, after) \\ Behavioural support \\ Food and non-food management \\ (3a) “When she steals food, I was talking about it feels wrong to discipline her, because she can't help it, but at the same time, I want her to know that she shouldn't be stealing food. So, just being able to talk, and the fact that they [psychologist and dietitian] were in the room together really helped" (Mother of Belinda, after) \\ (3b) "She [mother] can't even... well, she's powerless... she's glued at home with him, [...] And it has been like that where it's kicked off, he's had to be restrained, everything [...] It's quite sad, isn't it?" (Father of Jason, before) \\ (3c) "I'm very much aware that things are going to get harder as she gets older and I want to be proactive rather than reactive. I want to be on the \\ Managing developmental ball and the more I can do to learn and to meet people, and just the more I can do to be prepared, the better." (Mother of Belinda, after) milestones (3d) "It's going to be quite a big shift when she goes to school in September, especially with the behavioural stuff. You know, if they come to us and say, "She's been doing this today," it's like, "Okay, we don't know how to do this, we don't know what to tell them", because we know how to deal with it when it's us but not when she's left" (Father of Freya, after)}

\section{Social support}

(4a) "But we do need... The thing is what I struggle with is getting him doing activities, because there's nothing around my way for disability... children with disabilities, and, basically, if there is [...] but they want $£ 30$ a day, and there's no... You know, that's the reason why he can't"

Respite and activities (Mother of Jason, before)

(4b) “...my mum died, so we don't even have my mum. Another lady who used to help a lot has got Alzheimer's and obviously I can't rely on that family because they've got enough of their own woes" (Mum of Alice, after)

Financial (4c) "There's nothing for him. Well, there is, but you've got to pay for it" (Mother of Jason, before)

support (4d) “The biggest thing, really, is we've got DLA [disability learning allowance] due through now and I just don't know how to word stuff, so that's really frustrating for us. We do feel that she is entitled to it." (Mother of Sarah, before)

(4e) "School are brilliant. Yes, school are fantastic. They do lots of clinics and the dentist comes to the school as well so [...] No, I do"t think she'd cope anywhere else. It's the best facility for her, it really is" (Parent of Abigail, before)

School (4f) "The school have just fobbed us off [...] they haven't even put the lunch boxes out of sight [...] I mean they won't go to the toilet with her because they say they haven't got enough staff and they won't want a one-to-one, they don't encourage it, they say it's not healthy for the child because they get too attached" (Mother of Sarah, before)

\section{Connections and community}

(5a) "It's not like you can talk to the school mums, like I would with my other children. I can't say, "Oh, is he doing this and that? [...] To me, that

Connections to is the most useful, because other parents that've done it- which is why I think it would nice today, if I get see other parents in the waiting room, other families it's just, again, another reassurance that we're all in the same boat and we're doing what we can" (Mother of Belinda, before) (5b) "But it's always scary seeing the adults and stuff who have it, because it's looking into the future, before we are ready. But the future is always changing, the research is always changing..." (Mother of Freya, after)

(5c) "I'm always ringing them up, PWS to ask for- when it comes to things like- do you know? [...] Obviously they know what they're talking Connections to about these people." (Father of Jason, after)

PWS charities (5d) "The PWSA, the charity, or the FPWR the charity, they could be useful, kind of thing, liaising. So, they maybe a representative for them here" (Parent of Freya, after)

(5e) "Obviously, the conferences are either alternate years or really random and far away, but to be able to offer here some of the expertise locally Connection to to us, that would be really good" (Mother of Alice, after)

research (5f) "Any new research, happy to have that. That would be really good. Any clinic trials, I'm happy for her to be involved in trials if there are any that she would be suitable for" (Parent of Abigail, before)

were also valued, particularly the parents of the older children who sought help for difficulties with violent outbursts, which had previously escalated to require police involvement in one case. They had previously refused offers of assistance, but they now felt they needed support to manage and were willing to accept this from the pilot clinic (Table 2, 3b). 


\section{Managing Developmental Milestones}

The families reported that the consistency of the clinic would enable them to feel more supported throughout times of change (Table 2, 3c). Parents valued having clinical input on adjustments such as moving schools or their child progressing to independent living and also felt this expert input made them feel more equipped to share this knowledge with other key caregivers (Table 2, 3d).

\section{Social Support}

The inclusion of a social worker was integral to the family's experience of the clinic. Many families were juggling their child's care needs with the support of their wider families, without having access to the full range of support available to them.

\section{Respite and Activities}

Families were often not receiving formalised support packages. Therefore, for those who were not able to pay, children had little access to extra-curricular activities or social time with peers (Table 2, 4a). Parents of the older children specifically raised this "The two main things are respite and activities for him" (Mother of Child E, after). When children did attend activities, the parents reported being required to stay with their child, thus negating any respite effect and giving them little time for themselves or other family needs. Some families were occasionally supported by informal respite time with grandparents or friends. However, this was felt to be non-sustainable (Table $2,4 b)$.

\section{Financial Support}

Finances were a perceived barrier to improving the child's wellbeing, independence and making dietary change (Table 2 , 4c). Families were not always aware of the extent of the support available to them, and how to access it. The social worker was able to support with this, and families saw this as an asset to the clinic (Table 2, 4d).

\section{School}

School was a polarising experience for the families. Some parents reported schools being extremely supportive, typically those at special educational needs schools. These families had access to a wider range of support and additional health care facilities (Table 2, 4e).

Other families reported their child's school to be unsupportive, offering little in the way of additional assistance. These families perceived the prospect of the clinic's nurse and social worker aiding mediations with schools as an advantage.

\section{Connections and Community}

There was variability in knowledge about PWs across the families interviewed, and also the extent to which they were connected to other services and families.

\section{Connections to Other Families of Children with PWS}

Some families reported feeling isolated from others with PWS. Those who had engaged in either in-person or online support groups reported them to be a beneficial source of camaraderie and advice, as well as allowing parents to give back and support others. The clinic was felt to be beneficial in offering further opportunities to meet other families, regardless of their current level of connection (Table 2, 5a).

It is important to note that one family expressed that they had had concerns prior to the clinic about meeting older children with PWS due to an apprehension of experiencing what their life may be like in the future (Table 2, 5b).

\section{Connection to PWS Specific Charities}

The advice from, and connection to, PWS charities including Prader-Willi Syndrome Association (PWSA) and Foundation for Prader-Willi Research (FPWR) were highly valued. Even one family that refused most help, regularly contacted charities for advice (Table 2, 5c). Parents felt that having a representative from these organisations at the clinic would be beneficial (Table 2, 5d).

\section{Research}

Families sought to stay informed with the latest developments but feared that they would miss out due to the complex wording of academic works, and the geographical and cost barriers to attending conferences. Parents felt that having a professional who could summarise what recent research findings mean for their family would be advantageous (Table 2, 5e). Families were willing for their children to take part in research and were keen to support developments in PWS treatment and understanding (Table 2, 5f).

\section{Discussion}

Parents in this preliminary study felt that the MDT clinic facilitated the holistic care required to manage their child's diverse needs. The clinic was perceived to be a potential hub for their child's care (7), a sounding-board where families could share concerns and keep up-to-date with developments. Families felt a sense of apprehension about what the future held, knowing that their child's condition and thus the challenges they faced would vary with age (7). By having consistent appointments, potentially every six months (6), throughout their child's life, families were 
optimistic that the clinic could offer sustainable management that would enable concerns to be pre-empted (7). As access to specialist care is currently not universally accessible (PWSA UK, 2019) this clinic would facilitate equal access to all in the region, regardless of geography or finances.

Families understood the MDT clinic to enable integrated care, with enhanced communication and reported comingaway with tangible, implementable actions, without lengthy referral times. Families in this review were more concerned about treatment outcomes involving health and social integration, and less directly concerned about weight. Centres of excellence for PWS care have been suggested to support socialisation by including family-based therapeutic options, liaising with schools and developing education health and care plans $(6,9)$. This clinic goes further with an integrated social worker to implement links between healthcare, education, respite and activities to help their children thrive (10). Notably, the collaboration between the psychologist and dietician was valued, addressing the need to manage behavioural difficulties alongside the relationship with food (11). Parents suggested that other specialists who should attend the proposed MDT would be speech and language team members and specialists to help with concerns with, and these suggestions are consistent with guideline recommendations $(3,6,7)$.

Every family commented on how they valued meeting other families. Whilst clinics may not perceive peer support to be the primary function of this kind of appointment, other UK clinics do list this as an aim for their clinic (12). As families very much appreciated these relationships, help in accessing relevant charities and networks to obtain further connection would be valuable.

The clinic was considered to be practical and worked logistically. Long journey times were considered worthwhile to receive this standard of care. The MDT condenses some children's extensive calendar of appointments, reducing disruption; particularly important when the importance of routine $(11,12)$ and the high prevalence of autism or autismlike characteristics in children with PWS is considered (13). Whilst this long appointment was preferable, in the interest of quality, privacy and attention, families voiced the importance of a play-worker to support their child during possibly lengthy appointments.

The views expressed may be transferable to other similar regions where families do not have access to an MDT. Should the clinic trial the MDT approach as their core offering, this would open opportunities to both quantitatively and qualitatively evaluate patient outcomes in a larger trial. An economic evaluation of the cost-effectiveness of the service may also provide insightful, and important data outcomes at this point.

\section{Study Limitations}

It is important to note that all-but-one of these families were previously engaged with treatment. Thus, further work with families who are currently disengaged with care would help to create a service that has broader appeal. In order to maintain research impartiality, researchers were external, and the clinical team, with the exception of the social worker, were not involved in interviews. However, as the interviews took place in the same setting and researchers had an indepth understanding of PWS $(14,15,16)$, this division may not have been absolute and may have influenced responses.

\section{Conclusion}

Families felt the experience of an MDT clinic was superior to visiting the endocrinologist alone, enabling them to address issues around social support and behaviour in addition to health. They felt the sustained presence of a specialist clinic offered the support needed to feel competent in pro-actively meeting their child's needs.

\section{Acknowledgements}

The authors wish to thank the families who contributed to the writing of this paper, and the clinical staff members who ran the trial clinic, enabling this article to be conducted.

\section{Ethics}

Ethics Committee Approval: This work is a service article and thus no ethical approval was required. The service article had approval from Patient Experience and Involvement Team at University Hospitals Bristol and all interviewees provided informed consent to their participation and the publication of the results. All names used in this work are pseudonyms to protect the patient's anonymity.

Informed Consent: The service review had approval from the Patient Experience and Involvement Team at University Hospitals Bristol and all interviewees provided informed consent.

Peer-review: Externally peer-reviewed.

\section{Authorship Contributions}

Surgical and Medical Practices: Jennifer S. Cox, Claire Semple, Rhian Augustus, Melanie Wenn, Shelley Easter, Rebecca Broadbent, Dinesh Giri, Elanor C. Hinton, Concept: Jennifer S. Cox, Claire Semple, Rhian Augustus, Melanie Wenn, Shelley Easter, Rebecca Broadbent, Dinesh Giri, Elanor C. Hinton, Design: Jennifer S. Cox, Dinesh Giri, 
Elanor C. Hinton, Data Collection or Processing: Jennifer S. Cox, Rhian Augustus, Dinesh Giri, Elanor C. Hinton, Analysis or Interpretation: Jennifer S. Cox, Claire Semple, Rhian Augustus, Melanie Wenn, Shelley Easter, Rebecca Broadbent, Dinesh Giri, Elanor C. Hinton, Literature Search: Jennifer S. Cox, Dinesh Giri, Elanor C. Hinton, Writing: Jennifer S. Cox, Claire Semple, Rhian Augustus, Melanie Wenn, Shelley Easter, Rebecca Broadbent, Dinesh Giri, Elanor C. Hinton.

Financial Disclosure: This work received no external funding. This article was conducted by researchers funded by the GW4, MRC and the NIHR Bristol Biomedical research centre, Nutrition theme. The views expressed in this publication are those of the authors and not necessarily those of the NHS, the NIHR or the Department of Health and Social Care.

\section{References}

1. Butler MG, Miller JL, Forster JL. Prader-Willi syndrome - clinical genetics, diagnosis and treatment approaches: an update. Curr Pediatr Rev 2019;15:207-244.

2. Miller JL, Lynn CH, Driscoll DC, Goldstone AP, Gold JA, Kimonis V, Dykens E, Butler MG, Shuster JJ, Driscoll DJ. Nutritional phases in Prader-Willi syndrome. Am J Med Genet A 2011;155A:1040-1049. Epub 2011 Apr 4

3. Goldstone AP, Holland AJ, Hauffa BP, Hokken-Koelega AC, Tauber M; speakers contributors at the Second Expert Meeting of the Comprehensive Care of Patients with PWS. Recommendations for the diagnosis and management of Prader-Willi syndrome. J Clin Endocrinol Metab 2008;93:4183-4197. Erratum in: J Clin Endocrinol Metab 2010;95:5465. Epub 2008 Aug 12

4. Angulo MA, Butler MG, Cataletto ME. Prader-Willi syndrome: a review of clinical, genetic, and endocrine findings. J Endocrinol Invest 2015;38:1249-1263. Epub 2015 Jun 11

5. Cassidy SB, Driscoll DJ. Prader-Willi syndrome. Eur J Hum Genet 2009;17:3-13. Epub 2008 Sep 10

\section{Click for Appendix 1 access link: http://glns.co/4i1jz}

6. Duis J, van Wattum PJ, Scheimann A, Salehi P, Brokamp E, Fairbrother L, Childers A, Shelton AR, Bingham NC, Shoemaker AH, Miller JL. A multidisciplinary approach to the clinical management of Prader-Willi syndrome. Mol Genet Genomic Med 2019;7:e514. Epub 2019 Jan 29

7. McCandless SE; Committee on Genetics. Clinical report-health supervision for children with Prader-Willi syndrome. Pediatrics 2011;127:195-204. Epub 2010 Dec 27

8. Braun V, Clarke V. What can "thematic analysis" offer health and wellbeing researchers? Int J Qual Stud Health Well-being. 2014;9:26152.

9. Prader-Willi Syndrome Association UK. Prader-Willi Syndrome (PWS): Multi-Disciplinary Paediatric Health Oversight. Last Accessed date: 08.11.2021. Available from: https://nutrition2me.com/wp-content/ uploads/2019/02/Prader\%E2 \% 80\% 90Willi-Syndrome.pdf

10. Grosse SD, Schechter MS, Kulkarni R, Lloyd-Puryear MA, Strickland B, Trevathan E. Models of comprehensive multidisciplinary care for individuals in the united states with genetic disorders. Pediatrics 2009;123:407-412.

11. Allen K. Managing Prader-Willi syndrome in families: an embodied exploration. Soc Sci Med 2011;72:460-468. Epub 2010 Dec 14

12. Imperial Centre for Endocrinology. Prader-Willi Syndrome and genetic obesity. Last Accessed Date: 10.01.2020. Available from: http://www. imperialendo.com/for-patients/obesity-service/prader-willi-syndromeand-genetic-obesity

13. Dykens EM, Roof E, Hunt-Hawkins H, Dankner N, Lee EB, Shivers CM, Daniell C, Kim SJ. Diagnoses and characteristics of autism spectrum disorders in children with Prader-Willi syndrome. J Neurodev Disord 2017;9:18

14. Hinton EC, Holland AJ, Gellatly MS, Soni S, Patterson M, Ghatei MA, Owen AM. Neural representations of hunger and satiety in Prader-Willi syndrome. Int J Obes (Lond) 2006;30:313-321.

15. Holland A, Whittington J, Hinton E. The paradox of Prader-Willi syndrome: a genetic model of starvation. Lancet 2003;362:989-991.

16. Hinton EC, Holland AJ, Gellatly MS, Soni S, Owen AM. An investigation into food preferences and the neural basis of food-related incentive motivation in Prader-Willi syndrome. J Intellect Disabil Res 2006;50:633-642 